Article

\title{
Signaling the Adoption of the Benefit Corporation Model: A Step towards Transparency
}

\author{
Davide Galli $^{1}\left({ }^{1}\right.$, Riccardo Torelli $^{1, *}\left(\mathbb{C}\right.$ and Veronica Tibiletti ${ }^{2}$ \\ 1 Department of Economic and Social Sciences, Università Cattolica del Sacro Cuore, Via Emilia Parmense, 84, \\ 29122 Piacenza, Italy; davide.galli@unicatt.it \\ 2 Department of Economics and Management, University of Parma, Via J.F. Kennedy, 6, 43125 Parma, Italy; \\ veronica.tibiletti@unipr.it \\ * Correspondence: riccardo.torelli2@unicatt.it
}

check for updates

Citation: Galli, D.; Torelli, R.; Tibiletti, V. Signaling the Adoption of the Benefit Corporation Model: A Step towards Transparency. Sustainability 2021, 13, 6967. https:/ / doi.org/10.3390/su13126967

Received: 14 May 2021

Accepted: 15 June 2021

Published: 21 June 2021

Publisher's Note: MDPI stays neutral with regard to jurisdictional claims in published maps and institutional affiliations.

Copyright: (c) 2021 by the authors. Licensee MDPI, Basel, Switzerland. This article is an open access article distributed under the terms and conditions of the Creative Commons Attribution (CC BY) license (https:// creativecommons.org/licenses/by/ $4.0 /)$.

\begin{abstract}
Using the signaling theory as a reference, this research conducts an in-depth analysis of the adoption of the benefit corporation model, a legal and governance framework introduced into Italian regulations in 2016 following legislation introduced by many US states between 2010 and 2013. Focusing on the experience of Italian benefit corporations, we explore how these businesses manage their signaling environment (signaler, signal, receiver, and feedback) to obtain greater transparency. The analysis focuses on companies' bylaws, websites, and non-financial reports and suggests that the adoption of this new hybrid business model will only translate into an opportunity for greater transparency for one in four benefit corporations. The ability to strengthen the effects of adopting this model, adequate resources, and a long-term approach are required. The model, therefore, appears to present an opportunity for larger companies that have already invested adequately in the development of communication (web) and reporting (report) tools. The results seem to suggest that, on the contrary, for small companies with less experience, transformation into a benefit corporation may generate a risk of ambiguity.
\end{abstract}

Keywords: signaling theory; benefit corporation; transparency; impact reporting

\section{Introduction}

One of the most interesting phenomena that is affecting the debate on corporate responsibility is the growing number of companies that are transforming into benefit corporations [1]. Those companies are often seen as social organization 'hybrids' who try to combine profit orientation with the capacity to produce a social benefit [2]. This can be considered part of a broadened transition toward the development of a more responsible and transparent approach to business, but it presents three specific aspects [3]. First, a specific legal framework that clearly states the definition of a benefit corporation. In other words, the legislator determines what a benefit corporation is, while a similar definition does not exist for socially responsible or sustainable companies. Second, the introduction of this model, first in the United States and then in other countries, has created a formal option for companies to signal their commitment to specific purposes beyond stakeholder expectations and to report with greater transparency. Third, benefit corporations must be transparent about commitments pursued, both in terms of planning and reporting. Transparency thus becomes a central theme, since it extends from formal aspects, such as the adoption of the model, to substantial aspects, such as the impacts produced.

Starting from these specificities, this contribution analyzes the experience of benefit corporations in Italy, the first country, after the United States, to introduce this type of business into its regulatory framework (in 2015). The Italian context represents an interesting case, not only due to its uniqueness but also due to the concomitant adoption, first at the European Union level and then at the national level, of a discipline involving non-financial reporting (EU Directive 2014/95) that lays down the rules on the disclosure 
of non-financial and diverse information by large companies. Although a high degree of skepticism by academics still characterizes the debate on the effectiveness of this form of regulation, undoubtedly, the concomitant introduction of two tools-benefit corporations and non-financial reporting in the Italian context-has renewed interest and debate on the transparency of companies [4]. Indeed, transparency is a powerful theoretical and empirical concept that is capable of building trust between companies and stakeholders and solving problems connected to the possible decoupling between external communication and real performances [5]. This paper's aim is to interpret the Italian experience as a test of the ability of the benefit corporation model to become an effective signal for companies that want to generate an impact on their societies while also considering their profit orientation. The methodological framework adopted is that of signaling theory, which is useful for describing behavior when two parties (individuals or organizations) have access to different information. By adopting this theory, it is shown that the resources and experience gained over time increase the strength of the signal produced by the Italian benefit corporations through the adoption of this model, especially when accompanied by activation of a feedback mechanism. In contrast, organizational solutions, such as the appointment of a dedicated impact manager, do not seem to be so important. In light of the limited literature on benefit corporations, this study aims to bridge a gap in the international literature regarding how companies communicate their directional change towards a sustainable business model. This is an exploratory analysis that aims to provide preliminary answers by identifying interventions that can increase the level of transparency and present a more effective signal through the adoption of the benefit model so that effective solutions that meet the needs of different stakeholders and the challenges faced by company managers in terms of social and environmental commitments can be found. The empirical analysis is discussed through the four research hypotheses concerning the presence of a dedicated impact manager, the availability of company resources, the company's experience in adopting the benefit model and finally the timing of the activation of feedback channels.

The remainder of the paper is structured as follows: Section 2 presents a short overview of the benefit corporation model; Section 3 introduces the theoretical framework with a focus on signaling theory and its potential in the benefit corporation model; Section 4 describes the methodological approach used and presents the sample, the analysis method, the variables and the main results; in Section 5, a discussion is offered; and, in Section 6, some final remarks are given.

\section{A New a Type of For-Profit Corporate Entity: Benefit Corporations}

Over the past few years, the number of companies involved in what can be called a transition to the sustainability management model has grown significantly [6]. The further development of standards, frameworks, and approaches for the design and reporting of sustainable strategies has been fostered by the idea that the stakeholders' satisfaction and, more generally, their ability to actively manage the impacts on society and the environment, fall under the aegis of the company's own responsibilities $[7,8]$. These are heterogeneous initiatives, but all of them have the potential to become signals of a company's willingness to produce results than other than just shareholder profits [9].

Despite the large impact of these initiatives on corporate governance, strategies, and structures, the company's legal nature has only been questioned in a few cases. the social enterprise, the fourth sector, low-profit limited liability (L3C), community interest company (CIC), blended value, for-benefit, values driven, mission driven, and benefit corporation are some examples of hybrid organizations developed with the aim of reconciling profit orientation as a foundation of the corporate legal framework with the purpose of generating common benefits for communities and the environment [10].

The benefit corporation model is one of the most recent outcomes of this trend [11]. It was originally conceptualized by B Lab, a non-profit organization that promotes socially aware business practices by providing an opportunity for businesses to voluntarily 
adopt responsible decision-making standards [12]. A benefit corporation is a traditional corporation with modified obligations, committing it to higher standards of purpose, accountability, and transparency [13]. Benefit corporations commit to creating public benefit and sustainable value in addition to generating profit [14]. A benefit corporation is "legally obligated to pursue a public benefit in addition to its responsibility to return profits to the shareholders" [1]. It is a for-profit entity that has voluntarily and formally committed to creating social and environmental benefits in addition to its profit motive. With only small variations, state laws utilize a standard model to establish the benefit corporation status. benefit corporations must create a "general public benefit" and answer to shareholders.

According to US legislation introduced in 2010, the distinctive features of a benefit corporation are as follows: (1) it has the corporate aim of creating a material positive impact on society and the environment; (2) the duties of its directors are expanded and require the consideration of other interests in addition to the financial interest of its shareholders; and (3) it is required to provide yearly reports on its overall social and environmental performance through the use of a comprehensive, credible, independent, and transparent third-party standard. Thus, benefit corporations are legally for-profit, socially obligated, corporate forms of business, which combine traditional corporate characteristics with societal responsibilities (Appendix A).

The Italian version of the benefit corporation ("società benefit") was introduced at the end of 2015 (Appendix A). Italy was the first country in the European Union to introduce this new qualification into its company law. The benefit corporation is not a new type of corporation, but it is a corporation that can be included in one of the traditional categories and is intended to produce not only profit but also public benefits. The legal classification of the benefit corporation is related to provisions concerning the terms of its corporate purpose, which are connected to public benefits, and the provisions concerning obligations and their fulfilment and related responsibilities of the board of directors and of those who are entrusted with functions and tasks directed towards realizing public benefit [13]. The common benefits must be indicated in the corporate bylaws and must be pursued through a management strategy that aims to balance the interests of members those for whom social activity may have an impact.

Currently, Italian laws do not provide any particular benefit (tax relief or tax breaks) or explicit derogation compared with the ordinary rules of corporate law provided by the civil code and/or other regulatory provisions for benefit companies. They only provide a sort of 'reputational attribution', to which, presumably, the legislature may/will associate with in the future with further benefits in favor of entities that assume the status of a benefit company. Legal experts argue that the development of a law on benefit corporations in Italy was necessary because corporate legislation in Italy thus far has not easily allowed entrepreneurs to register companies with the double purpose of maximizing profits and producing common benefits. Since 2015, the number of benefit corporations in Italy has grown both in size and heterogeneity.

Looking at the recognition in national legislations in other parts of the world, the evolution and adoption of this new legal and business form is slowly increasing as of today (early 2021). While, in the United States, as pioneers in the recognition of this model, 37 states have implemented in their legislation a clear reference to the benefit model, and in Italy more than 500 companies have already adhered to this regulatory possibility, in the rest of the world this form of business is present in only six other countries: in Colombia and Puerto Rico from 2018; in Ecuador and Canada from 2019; in Peru from 2020; and in Rwanda from 2021 (Figure 1). France also has a "société à mission", similar to the benefit model but not adhering to the same criteria. 


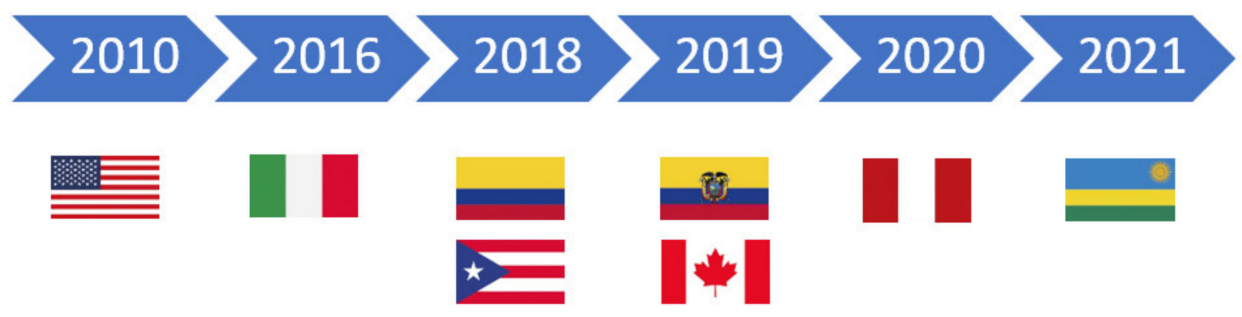

Figure 1. Legal recognition of benefit corporation.

\section{Interpreting the Adoption of the Benefit Model as a Signal: A Theoretical Framework}

Accounting and management scholars have recently started working on the recently introduced benefit company model. Focusing on research published in recognized journals and classified in major databases (e.g., Scopus), most studies, starting from the work of Andrè [3], have been conducted in the United States of America. Most of this research has focused on legislative aspects, primarily analyzing the differences between the applications of the benefit model in different States of the Union [15]. An added focus has been placed on the socioenvironmental commitment that characterizes US companies [16]. Analysis of this commitment has considered the importance of human rights aspects [17]. Additionally, an assessment of how socioenvironmental impacts are reported through online communication activity from a US/EU comparative perspective was conducted [17] Online communication has also been analyzed in depth by linking it to what is set out in the articles concerning the association of companies in five US states [3]. Although the US perspective is dominant, the Australian context has also been investigated through interviews with 14 companies, and the unique characteristics of companies oriented towards a sustainable business model have been investigated [11].

Signaling theory has been selected as the theoretical lens for analyzing and deepening our knowledge on the phenomenon of benefit corporations with specific attention given to transparency. It is a theoretical framework that is widely used in relation to environmental communication and sustainability issues [18]. It is also applied to issues related to obtaining corporate legitimacy [19]. Another focus is the internal company characteristics of communication (as well as its consequences) [20]. The adoption of the benefit model is closely linked to the abovementioned issues; it involves, more precisely, a company's decision to change its commitments, making its own social and environmental priorities and impacts explicit for several reasons (including obtaining legitimacy and reputation). This is a decision that can be communicated through different channels (i.e., impact reports, company websites, financial statements, and interviews). Reading the benefit corporation phenomenon through the lens of signaling theory suggests that the adoption of such a model can be interpreted as a "signal" that helps to provide a better understanding of potential motivation for the transformation and evolution of these hybrid organizations. Taking into account the essential components that distinguish this model-public purpose, accountability, transparency, company name, and destination of profits-it is evident that the change in the legal standards represents an important first signal. However, this signal needs to be appropriately amplified in order to reach those "receivers" for whom the company's benefits are produced.

Signaling theory greatly aids in the analysis and understanding of how two subjects with access to different information interpret the received signals. Connelly et al. focused their research on the role of signaling in understanding how parties attempt to solve the problem of information asymmetry [21]. Stiglitz highlighted how information asymmetry manifests itself when "different people know different things" [22]. There is a concrete attempt to solve the asymmetry, because it does not allow for correct knowledge of the characteristics (quality), behaviors, and intentions of others [23]. The concept of the signal is closely related to the concept of quality, defined as unobservable abilities of the signal giver [24]. 
The context offered by this theory within which the study of the signal was developed is a dynamic arena including temporal and evolutionary elements [21]. The present research, however, has a static character. We investigate a precise space-time moment without being able to analyze purely dynamic elements, such as variations in the signaling environment, changes in the receivers and their characteristics, and the effect of feedback on the signaler and, consequently, the new signal. The analysis carried out here is largely focused on the moment of sending the signal, highlighting its characteristics, and on the way in which it is constructed before being sent. This paper makes use of signaling theory to develop a preliminary interpretation of how Italian companies are exploiting the potential of the benefit corporation model to act as a signal.

The signaler is represented by an internal subject (e.g., a manager) who has relevant information about, for example, individuals, entire organizations, or products [25]. The basic assumption is that this information, whether positive or negative, is unknown outside, and that leads the individual to an advantageous position. Knowledge of this information gives the subject access to a better understanding of the real qualities of the entity (the company in our case), which, before the signal is launched, are unknown or not completely understood by the external subjects, who are not only external but also potentially internal. In the case of the benefit corporation, identification of the subject who internally promotes the adoption of the model is a central issue. Once the transformation has taken place, the role of signaler is assumed by the company, even when a specific responsibility in this regard is explicitly attributed to an internal subject. The present research considers two aspects related to the signaler that are relevant to the adoption of the benefit corporation model: the appointment of a manager who will report such a transformation, the company resources approximated by the level of revenue, and the number of employees. Thus, the following two research questions are discussed:

- RQ1: Is the adoption of the benefit corporation model as a signal strengthened by the appointment of a dedicated impact manager?

- $\quad R Q 2:$ Is the adoption of the benefit corporation model as a signal strengthened by a company's resources?

The signal is the communication that a subject gives about a quality that is otherwise imperceptible or unknown [21]. Usually this type of communication concerns positive qualities that, being known externally, can generate positive feedback. The application of signaling theory to the benefit corporation model suggests that a primary signal is produced by the adoption of this model and that this signal can be conveyed through different types of content. In this sense, the corporate bylaws, the annual impact report, and the company's website are the three most relevant documents in which the company can insert and articulate its signal by selecting a different mix of limited, extended, and open content types [26]. The adoption of the benefit corporation model can only be translated into a communication and transparency opportunity for the company if the signal reaches the public as widely as possible. The modification of corporate bylaws and the adoption of an impact report, which are the legal steps for effective transformation into a benefit corporation, do not ensure that the company's stakeholders and the public in general become aware of the impacts generated. For this reason, it appears plausible that, alongside the adoption of the model, companies develop adequate reporting tools over time that amplify the signal given about their transformation and the generated impacts. The following research question will be discussed:

- $R Q 3$ : Is the signal linked to the adoption of the benefit corporation model strengthened over time?

The receiver is a subject outside the company who has no direct information about the quality to which the signal refers. Often receivers and signalers have conflicting interests. The concept of the signal itself only makes sense if the receiver takes a certain type of action when it receives the signal and gets information about a certain quality. This is the so-called strategic effect of signaling, often associated with investment, financing, and 
hiring actions [21]. The most relevant receiver category in the case of the benefit corporation adoption is certainly the recipients of the positive impacts expected from the adoption of new purposes. These receivers do not necessarily understand the meaning of this signal. However, considering the different ways in which the signal can be transmitted, it appears possible to identify three types of receiver. The adoption of a new corporate bylaw constitutes a signal that is primarily intended for shareholders and potential stakeholders. Publication of the impact report creates a signal that extends to the most relevant stakeholders. The information transmitted through the website potentially radiates the signal to many categories of receivers. Further modulations of the receiver categories certainly depend on the content of the signal that the company decides to select. This research does not deepen the receiver analysis, limiting itself, on a conceptual level, to differentiating three types (shareholder, stakeholder, and the general public) on the basis of the document adopted (corporate bylaw, annual impact report, and the company's website).

Feedback is the receiver's response to the signaler, a sort of reaction to their communication and an evaluation of their work in terms of both message and action. The assumption behind the information asymmetry is its bidirectionality. The receiver would like information that the signaler has, and the signaler, in turn, would like information that the receiver has. In this sense, the receiver uses a countersignal that helps the signaler to understand the effectiveness and efficiency of the signal itself, its comprehensibility, and how it is interpreted [27]. The receiver's attention as well as the signaler's attention to feedback, if placed in an iterative and sequential sequence, lay the foundation for continuous improvement of the signaling and communication process [28]. The activation of feedback mechanisms appears fundamental in the case of the signal associated with the adoption of the benefit corporation model. First, this is related to the way in which shareholders react at the time of adoption as well as at a later date, as well as the impact that this transformation has on the dynamics of distributed profits. It concerns stakeholders who, in response to initiatives taken to satisfy certain interests, can react by offering or denying their support to the company and, above all, by contributing to the recognition of the benefits produced and the merit and reputation of the company. It concerns the general audience, who, over time, can attribute a positive meaning that is associated with a more positive attitude to the single benefit corporation as well as to the entire category. The activation of these mechanisms takes place over the medium to long term and certainly requires that the benefit corporation has specific forms of articulation when signaling to different types of receivers.

- RQ4: When is activated a feedback mechanism during the adoption of the benefit corporation model as a signal?

The signaling environment is a crucial element in the process of using a communication signal: it can create important distortions in terms of both how the signal is interpreted and how signalers are perceived [29]. A prominent role is played by the medium through which the signal is sent, which can increase or reduce the potential observability of the signal itself [30]. Additionally, the interpretation of the signal by other receivers can influence the way in which the remaining receivers interpret the signal [31]. This research focuses on the relationship between the signaler, signal, and the presence of feedback mechanisms, but it does not contribute to deepening the understanding of the dynamics between the signal and environment, leaving this aspect for further research. Below, we briefly describe the research questions investigated through the empirical analysis presented in the next section.

\section{Looking for a Signal: The Case of Italian Benefit Corporations 4.1. Sample}

In order to better understand if and how benefit corporations manage to transform the adoption of this model into an effective and transparent signal through the lens of signaling theory, this study explored the Italian benefit corporations' population at the beginning of 2020. The sample used for the analysis excluded micro-enterprises, that is, companies 
which, according to national legislation, have less than 2,000,000 EUR of revenue and less than 10 employees. The sample consisted of a group of 53 Italian companies, only including ten big companies: Chiesi Farmaceutici SpA, Henkel Italia Srl, Assimoco SpA, Aboca SpA, Fratelli Carli SpA, Davines SpA, Euro Company Srl, Abafoods Srl, NWG energia SpA, and Alessi SpA. As highlighted in Table 1, the surveyed companies had chosen to become benefit companies an average of 2.22 years before the end date of 31/05/2020. This is, therefore, an extremely recent phenomenon which is currently undergoing continuous and rapid evolution, as demonstrated by the presence of some companies in the sample that only became benefits in the past 0.3 years ( 2.5 months). That said, the sample also includes companies that have adhered to this legislative option since 2016. Regarding other corporate institutional dimensions taken into account, the total revenue, and the number of employees, at least $50 \%$ of the sample was made up of small companies (with less than 50 employees and less than 10 million EUR of revenue).

Table 1. Descriptive statistics of the sample.

\begin{tabular}{cccc}
\hline & $\begin{array}{c}\text { Years Since the Adoption } \\
\text { of the Benefit Model } \\
\text { (at 31 May 2020) }\end{array}$ & $\begin{array}{c}\text { Revenue in Thousands } \\
\text { of EUR (2018) }\end{array}$ & $\begin{array}{c}\text { Number of } \\
\text { Employees (2018) }\end{array}$ \\
\hline $\mathrm{N}$ & 53 & 53 & 53 \\
Mean & 2.22 & $45,271.06$ & 164.72 \\
Median & 1.80 & 5688.00 & 23.00 \\
Minimum & 0.30 & 0.00 & 1.00 \\
Maximum & 4.40 & $1,078,773.00$ & 3519.00 \\
\hline
\end{tabular}

\subsection{Method of Analysis}

The method of investigation was a content analysis of the three main communication tools relevant to the adoption of the benefit corporation model: corporate bylaws, impact report, and company website. Content analysis is a research method involving quantitative data collection that is widely used, especially for textual documents, in business economics and Corporate Social Responsibility studies [32]. In summary, the analyzed text was codified by defining a group of variables [33]. The collected data were subsequently subjected to the first exploratory analyses using descriptive statistics and correlation analysis to investigate potential relationships between variables. The empirical analysis then continued through the use of the cluster analysis method, in addition to highlighting the links between the different elements investigated in the company's communication/reporting system [34].

Data collection and coding was performed manually by the three authors independently and in its whole, and then compared to create the final coding. This was necessary in order to limit as much as possible errors due to manual compilation, typos and the subjectivity of the individual author.

\subsection{Description of Variables}

The variables related to the adoption of a benefit corporation's business model according to the theoretical perspective of signaling theory were grouped into three out of the four main components previously laid out: the signaler, the signal, and feedback. The receiver was deliberately excluded, because it was not possible to collect reliable or assessable information on the nature of the receiver of the company signal linked to the benefit form from the documents analyzed in the survey.

The first element analyzed, the signaler, was measured through a single ordinary variable assuming two possible values: 0 , the company does not indicate that it has a supervisor of corporate bylaw or the supervisor is generically the CEO or a member of the Board of Directors; 1 , the company indicates that there is a specific impact manager of bylaw, and the board of directors has no residual competencies. For the majority of 
Italian benefit corporations ( 30 of $53,56.6 \%$ ), a specific figure responsible for managing and monitoring impacts was identified.

The second element of the analysis was the signal. This element was measured by defining a set of six variables which together express the strength of the signal. Here, strength is a multidimensional concept encompassing all characteristics of the signal as a whole (including the bylaw, the website, and the impact report). Every positive or negative change in the individual signal characteristics (see Table 2 for characteristics and their descriptive statistics) leads to a change in the signal strength of the company regarding the adoption of the benefit model. We talk about strength, because a signal composed of a deeper and broader statute, intense web communication, and the presence of a report with a broader impact and attention to the communication modalities (impressions) should have a greater potential impact on the receiver and thus guarantee a more positive outcome for the company's communication as well as a greater level of transparency.

Table 2. Descriptive statistics of signal strength variables.

\begin{tabular}{|c|c|c|c|c|c|c|c|}
\hline & & Bylaw_Depth & Bylaw_Width & Web_Intensity & Report_Presence & Report_Width & Report_Impress \\
\hline \multicolumn{2}{|l|}{$\mathrm{N}$} & 53 & 53 & 53 & 53 & 53 & 53 \\
\hline \multicolumn{2}{|l|}{ Mean } & 0.30 & 0.33 & 0.34 & 0.62 & 0.28 & 0.11 \\
\hline \multicolumn{2}{|l|}{ Median } & 0.27 & 0.31 & 0.33 & 1.00 & 0.24 & 0.00 \\
\hline \multicolumn{2}{|l|}{ Mode } & 0.27 & 0.20 & 0.00 & 1.00 & 0.00 & 0.00 \\
\hline \multicolumn{2}{|c|}{ Minimum } & 0.07 & 0.08 & 0.00 & 0.00 & 0.00 & 0.00 \\
\hline \multicolumn{2}{|c|}{ Maximum } & 0.73 & 0.75 & 0.83 & 1.00 & 0.86 & 0.60 \\
\hline \multirow{3}{*}{ Percentiles } & 25 & 0.20 & 0.20 & 0.00 & 0.00 & 0.00 & 0.00 \\
\hline & 50 & 0.27 & 0.31 & 0.33 & 1.00 & 0.24 & 0.00 \\
\hline & 75 & 0.40 & 0.47 & 0.50 & 1.00 & 0.51 & 0.16 \\
\hline
\end{tabular}

1. Bylaw_depth: this variable was built to measure the depth with which the five impact areas identified by B Lab in its B impact assessment (governance, workers, community, environment, and customers) are considered in corporate bylaw. Through the content analysis of corporate bylaw an additive variable was measured-each of the five areas was given an index value relative to the level of specificity that distinguishes between absent, low, medium, and high $(0,1,2,3)$ based on the level of detail in the information communicated by the company. The results were translated in an ordinal index from 0 (no specific information for any areas) to 1 (high level of specificity for each of the five areas).

2. Bylaw_width: this variable was constructed to measure the extent to which the various issues belonging to the five impact areas identified by B Lab in its B impact assessment are considered in corporate bylaw. The most homogeneous themes were grouped together to obtain a total of sixteen macro-themes (Appendix A). Through an analysis of the corporate bylaws, we constructed an additive variable that was measured by attributing an index relative to the presence or absence of commitments and information about them to each of the sixteen macro-themes ( 0 , totally absent; 1 , totally present). The results were translated in an ordinal index from 0 (the absence of all macro-themes) to 1 (the presence of all sixteen macro-themes).

For the evaluation and measurement of the web signal, an additive variable that considered six measures related to the intensity of the signal launched through the company's website was developed.

3. Web_intensity: this contained six measures referring to: (i) the presence of information on the company's benefit status on the homepage; (ii) clearly visible positioning of information as evidenced on the page; (iii) the presence of a page dedicated to the information; (iv) the presence of an image of the impact manager on the dedicated webpage; (v) the presence of indicators or infographics on the dedicated webpage; and (iv) the presence of a link to the impact report on the website. The results were translated into an ordinal index with values of 0 (absence of all measures) to 1 (presence of all six measures). 
Further analysis was carried out on the impact reports. Three ad hoc variables were constructed in order to evaluate the signal launched through the impact reports.

4. Report_presence: this is a binary variable that measures the presence or absence of a public impact report ( 0 , absent; 1 , present). These data were collected from the analysis of the website and the search for the document on the web.

5. Report_width: this variable was constructed to measure the extent to which the various detailed issues belonging to the five impact areas identified by B Lab in its B impact assessment were considered in the impact report. As this is equivalent to the impact report of the measurement applied to the Bylaw_width variable, please refer to the descriptions of the 16 macro-areas. The results were translated in an ordinal index from 0 (absence of all macro-themes) to 1 (presence of all sixteen macro-themes).

6. Report_impression: this is a variable obtained from the sum of three indexes, each referring to a relevant dimension in terms of impression management applied to the drafting of the impact report. The three indexes are as follows: graphs and tables, which indicates the presence or absence of graphs and/or tables in the impact report with a binary value ( 0 , absent; 1 , present); images and figures, which indicates the presence or absence of images and/or figures showing relations with a binary value ( 0 , absent; 1 , present); and colors, which distinguishes whether colors are used or not in figures/images/tables/graphs or in normal text fields in the impact report with values from 0 to 1 . The results were translated in an ordinal index from 0 (low intensity of impression management) to 1 (full intensity of impression management in the impact report).

As can be seen from Table 2, the values obtained for Bylaw_depth and Bylaw_width were quite consistent and homogeneous. Having values of 0.30 and 0.33 , respectively, it can be seen that the companies with a certain level of breadth in terms of dealing with as many topics as possible among those measured are also the most inclined to consider deeper issues and provide more detailed information related to present and future commitments. The maximum values, equal to 0.73 and 0.75 , respectively, indicate a lack of breadth and depth in the consideration of relevant issues by Italian benefit companies. The Web_intensity on the web has extreme variability, as can be seen from the minimum and maximum values obtained, 0 and 0.83 , despite the fact that $75 \%$ of the companies studied stated that they cannot, or do not want to, exceed the value of 0.5 in 1 . As far as the signal launched through the impact report is concerned, the first data to be analyzed included the number of companies that published the report itself: $62.3 \%$, 33 of the 53 companies analyzed had published an impact report. The Report_width (when an impact report is present) has an average value slightly lower than the similar measure applied to the signal incorporated in the bylaw: 0.28 , with a minimum of 0 and a maximum of 0.86 . The variability in this case is higher since some companies, in the first percentile, have an amplitude equal to 0 (those that have not published a report), while others, in the third percentile, exceed the value of 0.5 . For the Report_impression, we obtained values between 0 and 0.6 and a rather low average of 0.11 . Only in the third percentile are there companies with a value higher than 0 .

The third and last element subject to analysis was feedback, which was measured with a specific variable (Feedback). For analysis purposes, the impact report is the point of focus for considering whether or not the information reported in this document actually allows the receivers to "react". In particular, the presence or absence of tools for the collection of feedback (other than corporate email) was considered. Only 13 of 53 companies $(24.5 \%)$ provide impact report tools that allow people to contact the company and give them feedback.

\subsection{Empirical Results: One Signal, Different Levels of Strength}

The correlation matrix of all the variables considered in the sample analysis on the adoption of the benefit corporation model highlights significant relationships that help us to better understand the factors influencing the approach of Italian companies (Table 3). 
Table 3. Spearman correlation matrix.

\begin{tabular}{|c|c|c|c|c|c|c|c|c|c|c|c|}
\hline \multirow{2}{*}{ Variables } & \multicolumn{3}{|c|}{ Corporate Institutional Dimensions } & \multirow{2}{*}{ Signaler } & \multicolumn{6}{|c|}{ Signal } & \multirow[b]{2}{*}{ Feedback } \\
\hline & _Years & Revenue & Employees & & Bylaw_Depth & Bylaw_Width & Web_Intensity & Report_Presence & Report_Width & Report_Impression & \\
\hline Years & 1.000 & 0.018 & -0.030 & -0.070 & -0.160 & -0.187 & 0.092 & $0.492 * * *$ & $0.562 * * *$ & $0.572 * * *$ & $0.245 *$ \\
\hline Revenues & & 1.000 & $0.632 * * *$ & -0.085 & -0.170 & 0.041 & 0.348 ** & 0.132 & 0.177 & 0.138 & $0.318^{* *}$ \\
\hline Employees & & & 1.000 & -0.133 & -0.031 & 0.077 & $0.313^{* *}$ & 0.130 & $0.327^{* *}$ & $0.245^{*}$ & $0.489 * * *$ \\
\hline Signaler & & & & 1.000 & -0.086 & -0.064 & 0.017 & 0.025 & -0.127 & -0.117 & -0.120 \\
\hline Bylaw_depth & & & & & 1.000 & $0.689^{* * * *}$ & 0.272 ** & -0.053 & -0.023 & -0.073 & -0.151 \\
\hline Bylaw_width & & & & & & 1.000 & $0.273^{* *}$ & -0.157 & 0.036 & 0.054 & 0.046 \\
\hline Web_intensity & & & & & & & 1.000 & $0.287^{* *}$ & $0.325^{* *}$ & 0.136 & 0.176 \\
\hline Report_presence & & & & & & & & 1.000 & $0.819^{* * *}$ & $0.668 * * *$ & $0.444^{* * *}$ \\
\hline Report_width & & & & & & & & & 1.000 & $0.789 * * *$ & $0.650 * * *$ \\
\hline Report_impression & & & & & & & & & & 1.000 & $0.466^{* * *}$ \\
\hline Feedback & & & & & & & & & & & 1.000 \\
\hline
\end{tabular}

${ }^{*} p<0.10 .{ }^{* *} p<0.05 .{ }^{* * *} p<0.01$ 
The first element that emerges from the analysis of the experience of Italian benefit corporations is that, for the time being, the person to whom the task of managing and reporting the outcomes produced for the community is entrusted does not seem to be a relevant variable (RQ1). This result, which focuses on a governance aspect, can probably be explained by the fact that the benefit model underlines the importance of the broad involvement of all corporate responsibilities. In addition, the model was introduced a few years ago, and it is likely that the "public impact report manager" has not yet emerged as a figure independently from roles with existing responsibilities. However, although this figure is expressly provided for by law, it does not seem strictly necessary for it to correspond to an ad hoc organizational position; if anything, it can be added to already existing positions, such as the CEO or CFO. This overlap has advantages and limitations that should be explored in further research.

The width of the signal transmitted via the web is significantly related to the dimensional characteristics of the company: larger companies with more employees contain information on their websites regarding their transformation into a benefit corporation and the impact generated. The signal's strength has been indirectly linked to the availability of adequate and continuous resources over time (RQ2). The designing and building of a signal are resource-intensive processes, and it is clear that larger companies may have more resources at their disposal (or obtain them when necessary) in terms of financial resources, attention, and dedicated people. Here, this characteristic is linked to the intensity of webbased communication, which is an integral part of the strength of the signal launched by the company.

The data seem to give an interesting answer to RQ3, especially with reference to the signal transmitted through the impact report. In addition to the resources available, the concept of experience appears in relation to the strength of the signal. The presence of an impact report, the depth of its contents, and the level of sophistication in impression management techniques are related to the temporal dimension. In other words, companies that have adopted the benefit model for several years are also those that develop reports with more complex contents. These companies also use images and graphics to explain their actions and results more effectively.

These results indicate how the level of signal strength and transparency of the company's communication on its socioenvironmental commitments are effectively related to the type of signal chosen. The publication of an impact report and communication via the internet lead to the production of an open signal that is more transparent and more effective in terms of information.

Lastly, the results give some insights related to RQ4. The results highlight that feedback collection takes place by companies that have increased the strength of the signal through the adoption of an impact report. Companies that present a more articulated impact report and that manage their web communication in a more sophisticated way are also those that provide feedback tools. These are also the largest companies in terms of revenue and employees that have become benefit corporations. The search for feedback is aimed at increasing transparency and contact between the company and stakeholders. The possibility of communicating in a bidirectional way ensures that information is conveyed more effectively and directly, and more specific requests from particular groups of stakeholders are responded to.

As an additional step in the analysis of the relationship between the adoption of the benefit corporation model and the signal strength and transparency, a top-down soft cluster analysis was implemented by adopting the stepwise backward elimination method and obtaining a fair silhouette measure of cohesion and separation. Through the elimination of non-significant variables that could not guarantee the quality of the clusters, seven predictors were selected (Years, Revenue, Web_intensity, Report_presence, Report_width, Report_impression, and Feedback), and three reference clusters were generated (Table 4). The presence of the impact report, the width of its contents, and the presence of feedback tools were identified as the most important variables (predictors), and these can be used to 
define three different clusters. Cluster 3 (20 companies, $37.7 \%$ ) is characterized by lacking a public impact report and feedback tools; this cluster is also characterized by a low-intensity web signal, a lower level of revenue, and less experience in the adoption of the benefit model. Cluster 2 (20 companies, 37.7\%) includes companies that, despite not having a feedback tool, have decided to publish an impact report; these companies also have a more intense web signal than those in Cluster 3 as are older and with much higher revenue. These companies have more experience and resources and have been using impact reports as a signal for some years. Cluster 1 (13 companies, 24.5\%) groups together companies that, in addition to having an impact report, also offer a tool for collecting feedback from receivers. These companies are always characterized by having a high level of revenue and a higher level of experience. It is important to point out that, in this cluster, there is also a much more intense web signal, a greater use of impression management tools in the impact report, and a much higher report width than in Cluster 2.

Table 4. Cluster details.

\begin{tabular}{|c|c|c|c|}
\hline Cluster & 1 & 2 & 3 \\
\hline Lable & Report_presence and Feedback & Report_presence & None \\
\hline Size & $24.5 \%(13$ of 53$)$ & $37.7 \%(20$ of 53$)$ & $37.7 \%$ (20 of 53$)$ \\
\hline Inputs & Report_width & Report_width & Report_width \\
\hline predictor importance 1.0 & 0.62 & 0.34 & 0.00 \\
\hline Predictor importance 0.8 & $\begin{array}{c}\text { Feedback } \\
1.00(100 \%)\end{array}$ & $\begin{array}{c}\text { Feedback } \\
0.00(100 \%)\end{array}$ & $\begin{array}{c}\text { Feedback } \\
0.00(100 \%)\end{array}$ \\
\hline Predictor importance 0.8 & $\begin{array}{c}\text { Report_presence } \\
1.00(100 \%)\end{array}$ & $\begin{array}{c}\text { Report_presence } \\
1.00(100 \%)\end{array}$ & $\begin{array}{c}\text { Report_presence } \\
0.00(100 \%)\end{array}$ \\
\hline Predictor importance 0.6 & $\begin{array}{c}\text { Report_impression } \\
0.26\end{array}$ & $\begin{array}{c}\text { Report_impression } \\
0.11\end{array}$ & $\begin{array}{c}\text { Report_impression } \\
0.00\end{array}$ \\
\hline Predictor importance 0.4 & $\begin{array}{l}\text { Year } \\
2.73\end{array}$ & $\begin{array}{l}\text { Year } \\
2.65\end{array}$ & $\begin{array}{l}\text { Year } \\
1.46\end{array}$ \\
\hline Predictor importance 0.2 & $\begin{array}{c}\text { Web_intensity } \\
0.46\end{array}$ & $\begin{array}{c}\text { Web_intensity } \\
0.38\end{array}$ & $\begin{array}{c}\text { Web_intensity } \\
0.23\end{array}$ \\
\hline Predictor importance 0.2 & $\begin{array}{l}\text { Revenue } \\
52,018.62\end{array}$ & $\begin{array}{l}\text { Revenue } \\
61,832.85\end{array}$ & $\begin{array}{l}\text { Revenue } \\
24,323.35\end{array}$ \\
\hline
\end{tabular}

The Cluster analysis adds insights related to research questions 2, 3, and 4 and seems to indicate the stages of a progressive evolution towards an increasing signal strength and transparency from those companies that adopt the benefit corporation model.

\section{Final Discussion: Theoretical and Empirical Contributions}

Small businesses (RQ 2) that adopted the model a few years before (RQ 3) are likely to develop weak signals that risk not being transparent and not producing the return that companies expect in terms of reputation and visibility. In particular, the use of particularly intensive and appropriate online communication systems is related to company size, as shown in the correlation analysis (see Table 3). Companies with greater resources (RQ 2) and experience (RQ3) develop more sophisticated and effective impact report tools, making the signal extended and perceptible for the stakeholders to whom the reporting documents are addressed. The communication tool contained in the impact report is significantly linked to the experience factor, i.e., the time since the company made its change in business model (see Table 3 for details). However, it is with the presence of adequate resources that the company further improves and extends the contents of the reports and activates feedback mechanisms (RQ 4) that significantly increase the level of transparency both in terms of the impacts produced and the very nature of the benefit corporation. Linked to the feedback tool is not only the size of the company but, above all, the experience and even more so the strength of the signal in relation to the impact report (Table 3 ). This communication tool is particularly linked to the feedback tool and the company's willingness to activate two-way communication. 
All of these factors provide the first useful elements for a reflection about our research questions. It is important to note that these are only the first experiences of a phenomenon which is still very young and constantly growing and changing have been analyzed. It can be seen that there is still a lack of mutual reinforcement mechanisms and that the results and variables linked to the impact report prevail, because it is a tool intended for reporting results, and therefore, it is more widely used for communicating these changes in the business model. This analysis of the experience of Italian companies allows us to propose some reflections both about the signaling theory theoretical framework and the benefit corporation concept.

In regard to the first aspect, it appears to be useful to discuss the connection between signaling theory and the concept of transparency through corporate disclosure. One of the most relevant risk factors for organizations that invest in communication about their behavior in favor of issues relevant to the general community is that it can create skepticism and generate mistrust [35]. Moreover, the communication and reporting of a specific social or environmental commitment, especially when it is not followed by real implementation of that commitment, can generate serious and very negative effects for the company in terms of both reputation and legitimacy, leading to skepticism by stakeholders and shareholders. This is especially evident when it comes to proactive behavior, i.e., communicating a goal or a commitment before implementing the associated actions [36]. The adoption of the benefit corporation model can be considered an example of proactive behavior that must be adequately signaled with reference to both the nature of this transformation and by reporting the impacts generated. A risk for benefit corporations is failing to reconcile the goals of generating profits and producing a positive impact. A less evident, but equally important, risk is not being able to strongly communicate the beneficial nature and positive impacts generated. The result is ambiguity: the company changes its nature to be transparent but then gets lost when trying to send a strong signal to the right receivers and promptly collect their feedback [37].

Our findings reinforce the potential of using signaling theory as a theoretical framework to provide a better understanding of how companies can translate the adoption of the benefit corporation model into a strong signal to increase their transparency. At the end of a thorough literature review on the subject, Schnackenberg provides this definition of transparency, "Transparency is the perceived quality of intentionally shared information from a sender" [5]. The signaling environment, as described by Connelly et al. [37], can thus be further interpreted as the set of conditions and dynamics that influence the level of transparency perceived by subjects belonging to a system of relations.

Regarding the second aspect, the present research discusses how benefit corporations, acting as signalers, can strengthen their signal by deciding how to impact (intentionally or unintentionally) stakeholder perceptions though the development of corporate bylaw, impact reports, and website contents. The results show that many companies still do not pay enough attention to the transparency of this choice and the use of valid communication tools such as the impact report and the website. This is a limit that is probably inherent in the benefit corporation model itself, since it envisages that companies will produce a benefit, but does not require them to engage the recipients of this benefit in the decisionmaking process. This involvement is an important requirement in all processes in which a company wants to produce relevant and transparent impacts for its stakeholders. The introduction of such a requirement could increase the transparency of these companies and eliminate or diminish the skepticism and suspicions of a commitment made in words but not through deeds. Greater openness to the outside world can also increase the trust and legitimacy of the reporting company as well as increasing their competitive advantage in the target market [37]. In this context, the data collected by this study, despite being partial, can be used as a valuable and useful starting point for managers facing the issues of effectively signaling their companies' commitments and managing the negative and positive impacts that this type of disclosure has on the company itself. 


\section{Conclusion: The Risk of Ambiguity}

The analysis of the Italian case has identified some potential useful insights regarding the adoption of the benefit corporation model that will have to be further investigated and confirmed by future research, even better if in different geographical contexts. First, the opportunity to clearly identify the role of the impact manager is evident and may ensure that their work is strongly integrated with other company processes. Although, based on the Italian experience, the analysis shows that this manager is not decisive in understanding the strength of the signal that the benefit corporations produce, it seems likely that the importance of this professional could grow over time. Secondly, the analysis shows how the reporting process linked to the adoption of the benefit corporation model and the related increase in transparency are located on a medium-long term time horizon. Therefore, the benefit corporation must constantly and periodically reproduce its signal, progressively amplifying its depth and width. These two considerations suggest that effective signaling by these companies is only possible in the presence of adequate resources, meaning that small companies risk developing greater ambiguity when adopting the benefit corporation model.

Research limitations concern the sample selection and size. First of all, micro benefit corporations were not considered, even if their size was relevant in the Italian context, hence the sample consisted of a group of 53 organizations. The research focused on Italy, given that it was the first country in Europe to adopt legislation for benefit corporations; however, it would be interesting to compare this legislation and its related impact with that experienced in other nations. Future research, for example, might consider a large cross-section for further analysis. A further limitation is the static nature of this analysis, which prevented the investigation of the dynamic elements of signaling theory, such as: the timeline of the signal; the movements from the signaler to the signal, the receiver, and the feedback; and the process of revision and improvement induced by responses from the external environment. These are elements of great importance which, nevertheless, require the implementation of analyses extended in both the spatial and temporal dimensions. Moreover, the role of receivers could be explored. Management research on signaling focuses, to a large extent, on shareholders as receivers in the signaling process. Future research might study the impact of signals on additional stakeholders. A last peculiar aspect that deserves attention in terms of potential further study is the regulatory framework, as the Italian legislator has introduced the benefit corporation model without providing any type of incentive. The results demonstrate how the presence and effectiveness of the signal ultimately depend on the resources that a company owns, and it is therefore very unlikely that the adoption of the benefit model will be effectively perceived by and produce actual benefits for small companies.

Author Contributions: Methodology, D.G.; Formal analysis, D.G.; Project administration, D.G.; Conceptualization, R.T.; Investigation, R.T.; Writing-Original Draft Preparation, R.T.; Resources, V.T.; Visualization, V.T.; Writing-Review and Editing, V.T. All authors have read and agreed to the published version of the manuscript.

Funding: This research received no external funding.

Data Availability Statement: Data are available upon request.

Conflicts of Interest: The authors declare no conflict of interest.

\section{Appendix A}

Law n. 208 of 28 December 2015, Comma 376.

"Those companies that:

a. in the exercise of an economic activity, in addition to profit-making, pursue one or more of the following activities for the common benefit;

b. operate in a responsible, sustainable and transparent manner towards people, communities, territories and environment, cultural and social assets and activities, bodies 
and associations and others stakeholders. The latter are defined as those subjects or groups of subjects that are directly or indirectly involved in the activity of the company, such as workers, customers, suppliers, lenders, creditors, public administration and society."

In order to apply the rule in question, these requirements both must occur conjointly: The first defines the purpose of the benefit company, which is represented by the interest of balancing a dual purpose of profit combined with social benefit; the second indicates the ways in which the business activity must be carried out and the subjects for whom it is intended to produce the relative positive effects. The benefit company is, therefore, an enterprise which — regardless of the size and type of activity carried out - can at the same time distribute profits and achieve common benefit purposes.

\section{Assonime, La disciplina delle società benefit. Circolare n. 19 del 20 giugno 2016.}

Next to the provision of the statement in the articles of association of the purposes of common benefit that the company intends to pursue 2016, the law is concerned with identifying the specific obligations incurred by the directors of the benefit company and the related responsibilities. These obligations, which are in addition to those provided by the civil code for the type of company chosen, concern in particular: (i) the management methods; (ii) the organization of the organization within the company; (iii) the accountability of the company.

Governance: (1) Mission and commitments; (2) Ethics and Transparency; Workers: (3) Financial security; (4) Health, well-being and safety; (5) Career development; (6) Engagement and satisfaction; Community: (7) Diversity, equity and inclusion; (8) Economic impact; (9) Civic involvement and donations; (10) Society and culture; (11) Supply chain; Environment: (12) Environmental management system; (13) Air and climate; (14) Water; (15) Earth and life; Customers: (16) Products and customer safety.

\section{References}

1. Hiller, J.S. The benefit corporation and corporate social responsibility. J. Bus. Ethics 2013, 118, 287-301. [CrossRef]

2. Rawhouser, H.; Cummings, M.; Crane, A. Benefit Corporation Legislation and the Emergence of a Social Hybrid Category. Calif. Manag. Rev. 2015, 57, 13-35. [CrossRef]

3. André, R. Assessing the Accountability of the Benefit Corporation: Will This New Gray Sector Organization Enhance Corporate Social Responsibility? J. Bus. Ethics 2012, 110, 133-150. [CrossRef]

4. Caputo, F.; Leopizzi, R.; Pizzi, S.; Milone, V. The Non-Financial Reporting Harmonization in Europe: Evolutionary Pathways Related to the Transposition of the Directive 95/2014/EU within the Italian Context. Sustainability 2020, 12, 92. [CrossRef]

5. Schnackenberg, A.K.; Tomlinson, E.C. Organizational transparency: A new perspective on managing trust in organizationstakeholder relationships. J. Manag. 2016, 42, 1784-1810. [CrossRef]

6. Loorbach, D.; Wijsman, K. Business transition management: Exploring a new role for business in sustainability transitions. J. Clean. Prod. 2013, 45, 20-28. [CrossRef]

7. Pedrini, M.; Ferri, L.M. Stakeholder management: A systematic literature review. Int. J. Bus. Soc. 2019, 19, 44-59. [CrossRef]

8. Lozano, R. Towards better embedding sustainability into companies' systems: An analysis of voluntary corporate initiatives. J. Clean. Prod. 2012, 25, 14-26. [CrossRef]

9. Frias-Aceituno, J.V.; Rodríguez-Ariza, L.; Garcia-Sánchez, I.M. Explanatory factors of integrated sustainability and financial reporting. Bus. Strategy Environ. 2014, 23, 56-72. [CrossRef]

10. Haigh, N.; Hoffman, A.J. Hybrid organizations: The next chapter in sustainable business. Organ. Dyn. 2011, 41, 126-134. [CrossRef]

11. Stubbs, W. Characterising, B. Corps as a sustainable business model: An exploratory study of B Corps in Australia. J. Clean. Prod. 2017, 144, 299-312. [CrossRef]

12. B Lab Is a Nonprofit That Serves a Global Movement of People Using Business as a Force for Good. B Lab's Initiatives Include B Corp Certification, Administration of the B Impact Management Programs and Software, and advocacy for Governance Structures Like the Benefit Corporation. Available online: https:/ / bcorporation.eu/about-b-lab (accessed on 15 March 2021).

13. Clark, W.H., Jr.; Babson, E.K. How benefit corporations are redefining the purpose of business corporations. William Mitchell Law Rev. 2012, 38, 8 .

14. Bauer, J.; Umlas, E. Making Corporations Responsible: The Parallel Tracks of the B Corp Movement and the Business and Human Rights Movement. Bus. Soc. Rev. 2017, 122, 285-325. [CrossRef]

15. Stecker, M.J. Awash in a Sea of Confusion: Benefit Corporations, Social Enterprise, and the Fear of "Greenwashing". J. Econ. Issues 2016, 50, 373-381. [CrossRef] 
16. André, R. Benefit corporations at a crossroads: As lawyers weigh in, companies weigh their options. Bus. Horiz. 2015, 58, 243-252. [CrossRef]

17. Nigri, G.; Michelini, L.; Grieco, C. Social Impact and Online Communication in B-Corps (SSRN Scholarly Paper ID 3071156; Issue ID 3071156). Social Science Research Network. Available online: https:/ / papers.ssrn.com/abstract=3071156 (accessed on 15 March 2021).

18. Mahoney, L.S.; Thorme, L.; Cecil, L.; LaGore, W. A research note on standalone corporate social responsibility reports: Signaling or greenwashing? Crit. Perspect. Account. 2013, 24, 350-359. [CrossRef]

19. Berrone, P.; Fosfuri, A.; Gelabert, L. Does Greenwashing Pay Off? Understanding the Relationship between Environmental Actions and Environmental Legitimacy. J. Bus. Ethics 2017, 144, 363-379. [CrossRef]

20. Basuroy, S.; Desai, K.K.; Talukdar, D. An Empirical Investigation of Signaling in the Motion Picture Industry. J. Mark. Res. 2006, 43, 287-295. [CrossRef]

21. Connelly, B.L.; Certo, S.T.; Ireland, R.D.; Reutzel, C.R. Signaling Theory: A Review and Assessment. J. Manag. 2010, 37, 39-67. [CrossRef]

22. Stiglitz, J.E. Information and the Change in the Paradigm in Economics. Am. Econ. Rev. 2002, 92, 460-501. [CrossRef]

23. Stiglitz, J.E. The Contributions of the Economics of Information to Twentieth Century Economics. Q. J. Econ. 2000, 115, 1441-1478. [CrossRef]

24. Spence, M. Job Market Signaling. Q. J. Econ. 1973, 87, 355-374. [CrossRef]

25. Kirmani, A.; Rao, A.R. No Pain, No Gain: A Critical Review of the Literature on Signaling Unobservable Product Quality. J. Mark. 2000, 64, 66-79. [CrossRef]

26. Granados, N.; Gupta, A. Transparency strategy: Competing with information in a digital world. MIS Q. 2013, 37, 637-641.

27. Gupta, A.K.; Govindarajan, V.; Malhotra, A. Feedback-seeking behavior within multinational corporations. Strateg. Manag. J. 1999, 20, 205-222. [CrossRef]

28. Srivastava, J. The role of inferences in sequential bargaining with one-sided incomplete information: Some experimental evidence. Organ. Behav. Hum. Decis. Process. 2001, 85, 166-187. [CrossRef]

29. Lester, R.H.; Certo, S.T.; Dalton, C.M.; Dalton, D.R.; Cannella, A.A. Initial Public Offering Investor Valuations: An Examination of Top Management Team Prestige and Environmental Uncertainty. J. Small Bus. Manag. 2006, 44, 1-26. [CrossRef]

30. Carter, S.M. The Interaction of Top Management Group, Stakeholder, and Situational Factors on Certain Corporate Reputation Management Activities. J. Manag. Stud. 2006, 43, 1145-1176. [CrossRef]

31. Sliwka, D. Trust as a Signal of a Social Norm and the Hidden Costs of Incentive Schemes. Am. Econ. Rev. 2007, 97, 999-1012. [CrossRef]

32. Guthrie, J. and Abeysekera, I. Content analysis of social, environmental reporting: What is new? J. Hum. Resour. Costing Account. 2006, 10, 114-126. [CrossRef]

33. Krippendorff, K. Content analysis. In International Encyclopedia of Communication; Barnouw, E., Gerbner, G., Schramm, W., Worth, T.L., Gross, L., Eds.; Oxford University Press: New York, NY, USA, 1989; Volume 1, pp. $403-407$.

34. Ketchen, D.J.; Shook, C.L. The Application of Cluster Analysis in Strategic Management Research: An Analysis and Critique. Strateg. Manag. J. 1996, 17, 441-458. [CrossRef]

35. Wagner, T.; Lutz, R.J.; Weitz, B.A. Corporate hypocrisy: Overcoming the threat of inconsistent corporate social responsibility perceptions. J. Mark. 2009, 73, 77-91. [CrossRef]

36. Barden, J.; Rucker, D.D.; Petty, R.E. Saying one thing and doing another: Examining the impact of event order on hypocrisy judgments of others. Personal. Soc. Psychol. Bull. 2005, 31, 1463-1474. [CrossRef] [PubMed]

37. Higgins, C.; Tang, S.; Stubbs, W. On managing hypocrisy: The transparency of sustainability reports. J. Bus. Res. 2020, 114, 395-407. [CrossRef] 